\title{
Combined FTIR Matrix Isolation and Density Functional Studies of Indole-3-Pyruvic Acid Molecule. Spectroscopic Evidence of Gas-Phase Tautomerism
}

\author{
Luigi Bencivenni, ${ }^{1}$ Andrea Margonelli, ${ }^{2}$ Alessandro Mariani, ${ }^{1}$ Andrea Pieretti, ${ }^{3}$ \\ and Stella Nunziante Cesaro ${ }^{4}$
}

${ }^{1}$ Dipartimento di Chimica, Università di Roma "La Sapienza", Piazzale Aldo Moro 5, 00185 Roma, Italy

${ }^{2}$ Istituto di Cristallografia (IC), Sezione Roma, Area Della Ricerca, Via Salaria Km 29,300, Montelibretti, 00016 Monterotondo, Italy

${ }^{3}$ Consorzio Interuniversitario per le Applicazioni di Supercalcolo per Università e Ricerca (CASPUR), via dei Tizii 6, 00185 Roma, Italy

${ }^{4}$ Istituto per lo Studio dei Materiali Nanostrutturati (ISMN) Sezione, Dipartimento di Chimica, Università di Roma "La Sapienza", Pizzalo Alido Moro 5, 00185 Roma, Italy

Correspondence should be addressed to Stella Nunziante Cesaro, stelluccia.nunziante@isnm.cnr.it

Received 12 January 2012; Accepted 13 February 2012

Academic Editors: T. Kar, A. Liwo, and T. Yamaguchi

Copyright () 2012 Luigi Bencivenni et al. This is an open access article distributed under the Creative Commons Attribution License, which permits unrestricted use, distribution, and reproduction in any medium, provided the original work is properly cited.

The vibrational spectrum of matrix-isolated indole-3-pyruvic acid has been studied aiming to obtain information about the structures of the stable vapour-phase forms of the molecule. Together with results from theoretical density functional calculations, the spectroscopic data enable to undertake an attribution for most of the observed bands. The FTIR spectrum of crystalline indole3 -pyruvic acid has been compared with that of matrix isolation study.

\section{Introduction}

The indole-3-pyruvic acid (IPA), see the attached chart, exerts a key role in different biochemical pathways.

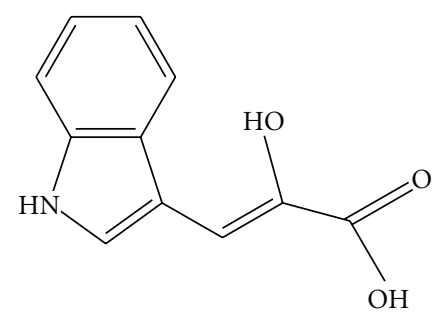

It is recognised, in fact, that IPA is the central intermediate in the production of the indole-3-acetic acid (IAA), which is the most important growth producer in plants $[1,2]$. It is also the direct precursor of the kynurenic acid (KYNA) in the mammalian organs, being an efficient antagonist of excitatory amino acid receptors [3], counteracting the oxidative stress which is believed to be involved in the pathogenesis of degenerative diseases, especially of the central nervous system. The activity of IPA in both biological processes seems to be ascribed to its hydroxy tautomer which is very efficient as free radical scavenger showing very high antioxidative properties [4-6].

IPA is known to exist in its hydroxy form in crystal state with four molecules in unit cell whose structure is stabilized by intermolecular hydrogen bonds occurring between the carboxy groups without the participation of the NH groups of the molecule. Strong interactions between indole rings seem to be excluded [7].

The equilibrium between the hydroxyl and keto forms of the molecule (see the chart below) 


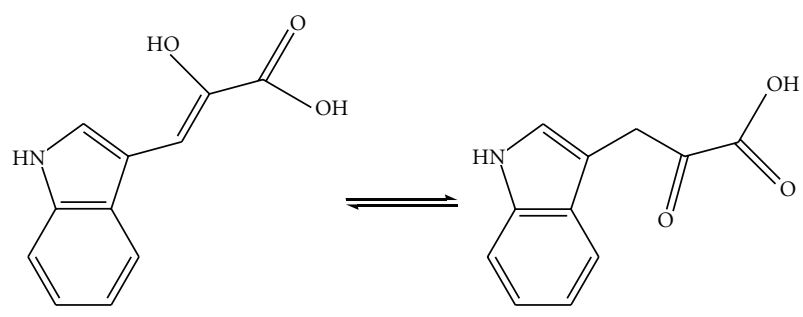

has been studied in several solvents of different acid-base character. It has been proved that the keto form is stabilised in protophilic solvents probably because of the presence of the $\mathrm{CO}_{2}{ }^{-}$anion [8]. IPA has been also tested as matrix in matrix-assisted laser desorption/ionization mass-spectrometry (MALDI-TOF) studies, together with some structurally related compounds such as 4-hydroxy-3-methoxyphenylpyruvic acid and indole-3-glyoxylic acid showing some effectiveness in case of small proteins desorption not requiring high laser intensity [9].

So far, no data are available about the tautomeric structure of IPA monomer without the complication of molecular association and consequent intermolecular interaction.

Since the knowledge of this aspect seems significant even for a deeper understanding of the biochemical pathways involving IPA, the FTIR spectrum of the single molecule was studied using matrix isolation technique, and the results of this work reported in this paper were compared to infrared spectroscopy data obtained in its solid state ([7] and this work). The interpretation of the matrix-isolated spectra was chiefly based on theoretical results obtained through densityfunctional calculations, and a further support for the assignment of the measured vibrational spectra of the molecule took into consideration previous results reached for monomeric indole [10], pyruvic acid [11], and tryptophan $[12,13]$.

\section{Experimental Section}

The infrared spectra of powdered samples (Aldrich) were recorded using a diffuse reflectance infrared (DRIFT) sampling accessory (Praying Mantis, Harrick).

Samples were intimately mixed to $\mathrm{KBr}$ (Aldrich, IR grade, $99.998 \%$ ) in the ratio $1: 100$ or less. The background spectra were recorded using about $100 \mathrm{mg}$ of powdered $\mathrm{KBr}$.

The spectra were obtained in the $4000-400 \mathrm{~cm}^{-1}$ range using a Bruker Equinox 55 Interferometer cumulating 200 scans for routine spectra with a resolution of $2 \mathrm{~cm}^{-1}$.

The matrix isolation technique was employed to record spectra of IPA in pseudogaseous state. The experimental assembly basically consists of a Bruker IFS 113v Interferometer coupled, through a suitable cesium iodide optical window with a high vacuum $\left(\sim 10^{-6}\right.$ torr $)$ shroud, in which a rotatable cryotip (Displex, Air Products and Chemicals, CSA 202) is installed. The shroud is coupled with a home-made resistively heated furnace. The vaporization temperature was monitored by a thermocouple. The pressure in this section was kept at $\sim 10^{-6}$ torr, while in the region of the interferometer was about $\sim 10^{-3}$ torr. Samples were vaporized from a graphite Knudsen cell in the temperature range 310-450 K, below the decomposition temperature value $488 \mathrm{~K}$ [9]. Temperature increasing within this range, holding other experimental parameters unchanged, caused enhancement of the intensity of the bands detected without appearance of new features. This observation ruled out any decomposition process of the sample. Equilibrium vapor over the solid sample was mixed to high purity argon in excess (99-99.8\%, Rivoira) flowing at rate about $1 \mathrm{mmolh}^{-1}$ through a standardized needle valve. Matrix gas and sample vapor were trapped on a gold plated copper coldfinger kept at $12 \mathrm{~K}$, and spectra were taken in reflection. Routinely performed annealing cycles up to $30 \mathrm{~K}$ did not affect the spectral features observed. Time taken to deposit matrices suitable for spectroscopic examination varied from 10 minutes to 4 hours.

The FTIR spectra were recorded in the $4000-400 \mathrm{~cm}^{-1}$ range cumulating 200 scans with a resolution of $1 \mathrm{~cm}^{-1}$. For a better understanding of the matrix-isolation spectra, bands due to water and carbon dioxide were subtracted, and consequently the FTIR spectra shown in this work do not reveal typical absorptions of these molecules trapped in argon matrix.

The calculations were run on the CASPUR-computing facility matrix. The cluster matrix is based on quad-core Opteron processor (Barcelona) consisting of 330 dual sockets computing nodes each equipped with 16 GB of RAM (a small part with $32 \mathrm{~GB}$ of RAM). IB DDR is used as fast interconnection device for multinode calculation and for high speed I/O using Lustre as distributed file system. Geometry optimizations, harmonic frequencies, and single energy point calculations were accomplished using the GAUSSIAN-03 program packages [14]. Molden program [15] was used as visualization tool for molecular structures and calculated IR spectra. Potential energy distribution (P.E.D.) was determined by VEDA program [16] for complete vibrational analysis.

\section{Results and Discussion}

Previous matrix-isolation FTIR spectroscopy studies performed on pyruvic acid [11] and tryptophan [12, 13] show that the vapour phase of these molecules is a quite complex one because a wide number of stable isomers are simultaneously present over the condensed phase of the molecule. In fact, the vibrational spectra of these species reveal typical spectroscopic features of the most stable and abundant isomers. Starting from this premise, the results accomplished from the infrared spectra of single IPA molecule and those obtained from theoretical calculations, which are of fundamental importance in the present context, will be reported and discussed together in this section. In order to decide whether a given isomer might be experimentally identified by means of vibrational spectroscopy, one has to rely on the results of theoretical calculations. Among the spectra of the matrix-isolated vapor phase of the molecule obtained from vaporization of the crystalline phase at variable temperatures within the range $310-450 \mathrm{~K}$, that recorded at $380 \mathrm{~K}$ temperature is taken as the reference FTIR spectrum for the presentation of our results. It is worthwhile observing that 
all the spectra recorded in this temperature range never provided evidence of bands due to possible decomposition products, confirming that IPA sample was actually kept below its decomposition temperature, $488 \mathrm{~K}$ [9].

Bearing in mind that IPA molecule consists of both indolic and pyruvic fragments, one has to expect that its argon matrix spectrum might reveal presence of several isomers of both its keto and hydroxy tautomers, as a consequence of possible orientations of the carboxylic groups of the pyruvic section of the molecule. For this purpose, one has first to take into account the existence of each hydroxy $(\mathbf{H})$ and keto $(\mathbf{K})$ form of the molecule and the corresponding stability and vapor phase population analysis in order to determine the overall theoretical DFT spectrum and to compare it with the experimental one.

For the combined experimental and computational analysis of the results, the regions of the FTIR spectrum to be examined in detail are that of the $\mathrm{NH}$ and $\mathrm{OH}$ stretching modes and those of the carboxylic groups, with particular reference to the $\mathrm{C}=\mathrm{O}$ stretchings, $\mathrm{C}-\mathrm{OH}$ in-plane bendings, and even stretchings. Another spectral region of great interest to be carefully considered is that of the $\mathrm{C}=\mathrm{C}$ stretching of the pyruvic fragment of IPA molecule, the presence of which would prove the existence of hydroxy forms. In fact, the presence of the different tautomers of the molecule produces typical infrared patterns, as actually reported for pyruvic acid [11] and tryptophan $[12,13]$, in particular for the $\mathrm{NH}, \mathrm{OH}, \mathrm{C}=\mathrm{O}$ stretching modes, and the $\mathrm{C}-\mathrm{OH}$ in-plane bending modes.

A wide number of hydroxy and ketonic structures of the molecules was considered for geometry optimization and vibrational frequency calculations at the B3LYP/6$311++\mathrm{G}^{* *}$ and B3PW91/6-311++G** levels. The most stable tautomers found from the calculations are denoted as $\mathbf{H}$ (hydroxy form) and $\mathbf{K}$ (ketonic form) and are shown in Figure 1. All of them were determined to be stable structures, that is, true energy minima of the molecule, from vibrational harmonic frequencies computations. An insight into the relative stability of the most stable hydroxy and keto tautomers was accomplished from G2MP2 calculations, and the energy differences were calculated at $0 \mathrm{~K}, 298 \mathrm{~K}$, as well as within the vaporization temperature range $350 \mathrm{~K}-450 \mathrm{~K}$ for thermal effects might be meaningful at mildly high temperature. The calculated G2MP2 energy differences are reported in Table 1 and are quite small for most of the tautomers, and the stability order basically remains unchanged with temperature increasing, at least for the lowest energy structures. Analysis of the tautomeric space of the molecule is extremely important for the knowledge of vapour phase population. Boltzmann populations of all the tautomeric forms were computed from standard Gibbs free energy functions, through the relationship $\Delta G_{T}^{\circ}=-R T \ln K$, being $\mathrm{K}$ the ratio between the molar fraction of a given gas-phase tautomer with respect to that calculated for the lowest energy H01 species and were examined at different temperatures. The G2MP2 energy differences, calculated with respect to the lowest energy structure at $0 \mathrm{~K}$, are reported in Table 1 along with vapour-phase population determined at $380 \mathrm{~K}$, that is, the average vaporization temperature of solid IPA sample. The conclusive picture seems to be quite clear, being
TABLE 1: Relative stability ${ }^{(a)}$ and gas-phase population at $380 \mathrm{~K}$ of the hydroxylic (H) and ketonic (K) forms of IPA molecule.

\begin{tabular}{lcccc}
\hline Tautomer & $\Delta E_{0}$ & $\Delta E_{298}$ & $\Delta E_{380}$ & Population $(\%)$ \\
\hline H01 & 0.0 & 0.0 & 0.0 & 24.1 \\
K02 & 1.0 & 1.0 & 0.6 & 40.5 \\
K03 & 5.7 & 5.8 & 5.4 & 13.1 \\
K04 & 8.4 & 8.9 & 8.55 & 9.0 \\
H05 & 10.75 & 11.2 & 11.3 & 1.1 \\
K06 & 10.8 & 11.3 & 11.0 & 4.6 \\
K07 & 11.6 & 12.1 & 11.8 & 2.9 \\
H08 & 12.8 & 13.0 & 13.0 & 0.9 \\
K09 & 13.85 & 14.4 & 14.1 & 1.6 \\
K10 & 18.3 & 19.0 & 18.7 & 0.4 \\
K11 & 19.4 & 20.4 & 20.1 & 0.7 \\
K12 & 23.0 & 23.6 & 23.6 & 0.05 \\
K13 & 26.1 & 26.9 & 26.7 & 0.2 \\
K14 & 26.1 & 26.9 & 26.6 & 0.1 \\
K15 & 30.3 & 30.4 & 30.1 & 0.0 \\
K16 & 30.8 & 29.2 & 28.6 & 0.0 \\
H17 & 31.8 & 32.2 & 32.2 & 0.0 \\
H18 & 33.3 & 31.0 & 30.25 & 0.0 \\
H19 & $40.1_{5}$ & 40.8 & 40.8 & 0.0 \\
H20 & 41.8 & 42.7 & 40.8 & 0.0 \\
H21 & 41.6 & 42.7 & 42.9 & 0.0 \\
\hline The & & & -1 & \\
\hline
\end{tabular}

The G2MP2 energy difference values $\left(\mathrm{kJ} \mathrm{mol}^{-1}\right)$ are calculated with respect to the lowest energy tautomer $\mathbf{H 0 1}$ and include zero-point vibrational $\left(\Delta E_{0}\right)$ and thermal plus zero-point vibrational energy $\left(\Delta E_{298}\right.$ and $\left.\Delta E_{380}\right)$ corrections.

the vapour phase consisting of appreciable amount of $\mathbf{H}$ and $\mathrm{K}$ type tautomers. At the reference temperature of $380 \mathrm{~K}$, the vapour is a mixture of several hydroxyl and keto forms and among them those labelled as H01, K02, K03, K04, $\mathrm{H05}, \mathrm{K06}$, and $\mathrm{K07}$ are the most abundant ones. The keto forms K02, K03, K04, K06, and K07 largely contribute to the vapour phase $(71.4 \%)$ whilst the hydroxy forms $\mathrm{H01}$ and H05 have a minor but rather than negligible contribute to the vapour phase (25.1\%), being, however, H01 the only hydroxy tautomer present in valuable amount $(24.1 \%)$. The fact that the lowest energy hydroxy tautomer $\mathbf{H 0 1}$ is not the most abundant one in the vapour phase shows the significant influence of entropic factor on stabilization of a given species at a specified temperature. That is particularly true when the $T \Delta S_{380}^{\circ}$ term is sufficiently larger, or at least comparable, than the $\Delta H_{380}^{\circ}$ value, as presently occurring, as well as for tryptophan [13] and phenylalanine [17]. Such a complex gas phase would reflect on the infrared spectrum of the vapour species measured in argon matrix at $12 \mathrm{~K}$ obtained from solid sample heating at $380 \mathrm{~K}$. Evidently, the largest contribute $(\sim 87 \%)$ to the actual infrared spectrum is due to the most abundant vapour-phase tautomers K02 (40.5\%), H01 (24.1\%), K03 (13.1\%), and K04 (9.0\%) although the minor contribution of the ketonic forms K06 (4.6\%) and K07 (2.9\%) and likely even that of H05 (1.1\%), and K09 (1.6\%) could not be thoroughly excluded. The vapour-phase composition was considered to predict the simulated spectrum, 


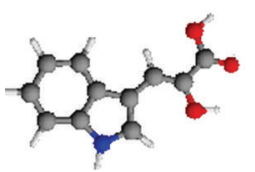

H01

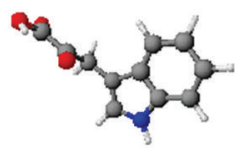

K04

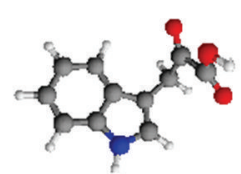

K07

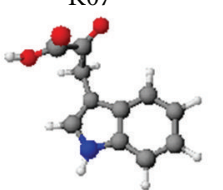

K10

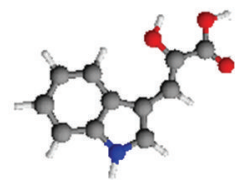

H13

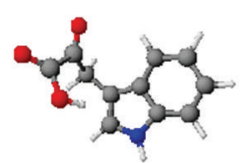

K16

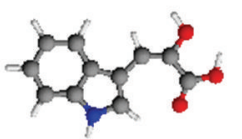

H19

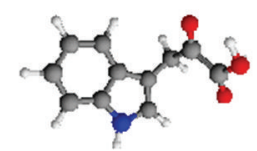

K02

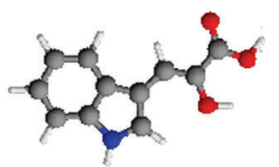

H05

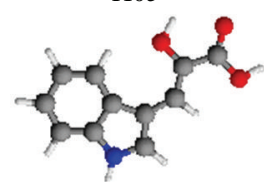

H08

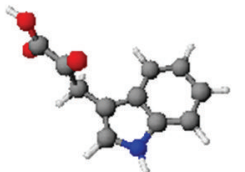

K11

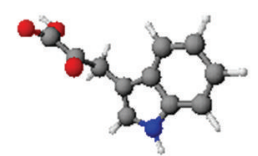

K14

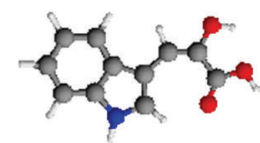

H17

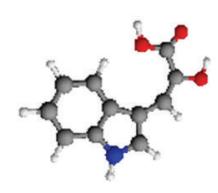

H20

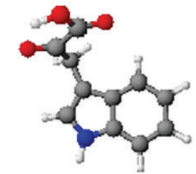

K03

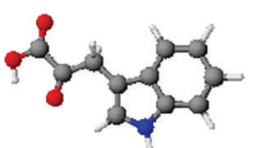

K06

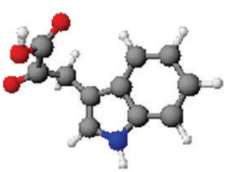

H09

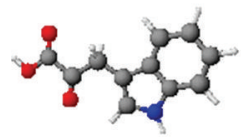

K12

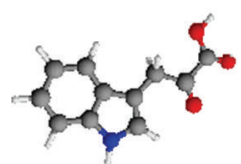

K15
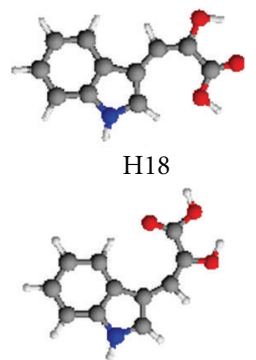

H21

FIgure 1: Structures of the Hydroxy (H) and Keto (K) Forms of IPA.

where the theoretical infrared-band intensity of each fundamental vibration was corrected by the statistical population calculated for each tautomer at $380 \mathrm{~K}$. The expected overall theoretical infrared spectrum (see Figure 2) is, therefore, the population-weighted sum of the calculated spectra of the individual forms expected to be present in the vapour phase, and it was carefully examined in the three distinct regions where bands were observed, that is, 1200$1900 \mathrm{~cm}^{-1}, 400-1200 \mathrm{~cm}^{-1}$, and $3000-3800 \mathrm{~cm}^{-1}$, and each theoretical spectrum was compared with the corresponding experimental one. The three infrared ranges of particular interest for the purpose of this work are those of the carbonylic and carbon-carbon double bond stretching frequencies, the infrared region of the $\mathrm{NH}$ and $\mathrm{OH}$ stretching frequencies, as well as the region of the $\mathrm{C}-\mathrm{OH}$ bendings, as most of these vibrational modes are predicted from the calculations to produce high-intensity bands.

IPA molecule has sixty-six fundamental vibrations $\left(45 \mathrm{~A}^{\prime}+21 \mathrm{~A}^{\prime \prime}\right.$ for the planar species), and among them, fiftyfive modes are predicted from the calculations within the range $400-4000 \mathrm{~cm}^{-1}$, that is, the range of our FTIR measurements in argon matrix. According to the calculations, the $\mathrm{NH}$ and $\mathrm{OH}$ stretching frequencies are distributed in the same high-frequency region of the infrared spectrum. These vibrations, as it is well known, suffer a high degree of anharmonicity, and calculated frequencies should be scaled by suitable scaling factors, which were determined by comparing the results of $\mathrm{B} 3 \mathrm{LYP} / 6-311++\mathrm{G}^{* *}$ calculations on 


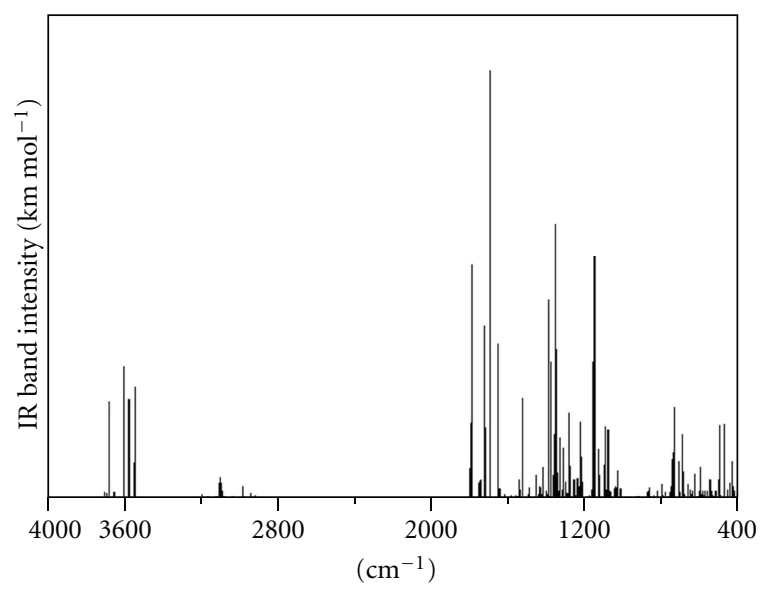

FIGURE 2: B3LYP/5-311++G** simulation of the IR spectrum of IPA in its vapor phase (the overall spectrum is the-weighted sum of the theoretical spectra of all the $\mathbf{H}$ and $\mathbf{K}$ type tautomers).

indole and pyruvic acid with the respective experimental stretching frequencies measured in gas-phase [18] and lowtemperature matrix [11]. Thus, the calculated $\mathrm{OH}$ and $\mathrm{NH}$ stretching frequencies were scaled by 0.94 and 0.96 , respectively. Another consideration to be taken into account is that calculated infrared band intensities of these vibrations, as well as of other normal modes, might be often unsatisfactory, and therefore they must be handled with particular judgment.

The NH bond present in the indolic group never participates to any intramolecular hydrogen bonding, and its stretching mode is always predicted from the calculations within $3523 \pm 5 \mathrm{~cm}^{-1}$ for all the hydroxy and keto species. The intense peak measured at $3514.5 \mathrm{~cm}^{-1}$ would therefore correspond to the $\mathrm{NH}$ stretching frequency of all the $\mathbf{H}$ and $\mathrm{K}$ species.

The $\mathrm{OH}$ stretching frequencies are strongly influenced by the structural surrounding of the $\mathrm{OH}$ bonds, and for this reason these vibrations are computed a hundredth $\mathrm{cm}^{-1}$ higher than the $\mathrm{NH}$ stretchings when the $\mathrm{OH}$ bonds are involved in weak intramolecular hydrogen bonding (i.e., 2.30 ) otherwise, when the $\mathrm{OH}$ bonds are involved in stronger intramolecular hydrogen bonding (i.e., $2.03-2.08 \AA$ ), the $\mathrm{OH}$ stretching vibrations are shifted to lower frequencies, even at wavenumbers comparable with the $\mathrm{NH}$ stretchings (see Table 2). Taking into account the most abundant species, one strong intramolecular hydrogen bond at $\sim 2.03 \AA$ is present in K02, K03, K04, and K06, whereas two intramolecular hydrogen bonds at $\sim 2.08 \AA$, and $2.29 \AA$ are present in H01. The structures of the tautomers $\mathbf{K 0 7}$ and K09 show weaker intramolecular hydrogen bonds at $\sim 2.32 \AA$, and the scarcely abundant $\mathbf{H 0 5}$ form has two well distinct intramolecular hydrogen bonds at $\sim 2.03 \AA$ and $2.30 \AA$. Keeping into consideration these structural features, reflecting on the calculated harmonic $\mathrm{OH}$ stretching frequencies, population analysis, the predicted frequencies of the $\mathrm{OH}$ stretching vibrations reported in Table 2, and the simulation of the theoretical spectrum obtained by summing the spectra of the
TABLe 2: $\mathrm{OH}$ and $\mathrm{NH}, \mathrm{C}=\mathrm{O}$, and $\mathrm{C}=\mathrm{C}$-scaled B3LYP/6-311++G** stretching frequencies $\left(\mathrm{cm}^{-1}\right)$ of the most abundant gas-phase species.

\begin{tabular}{lcccc}
\hline Tautomer & $\mathrm{OH}$ & $\mathrm{NH}$ & $\mathrm{C}=\mathrm{O}$ & $\mathrm{C}=\mathrm{C}$ \\
\hline K02 & 3418 & 3523 & $1780-1712$ & \\
H01 & 3551 & 3518 & 1684 & 1610 \\
& 3477 & & & \\
K03 & 3423 & 3523 & $1782-1708$ & \\
K04 & 3417 & 3527 & $1785-1728$ & \\
K06 & 3421 & 3526 & $1787-1713$ & \\
K07 & 3523 & 3525 & $1744-1738$ & \\
K09 & 3522 & 3524 & $1740-1737$ & \\
H05 & 3571 & 3518 & 1734 & 1601 \\
& 3560 & & & \\
\hline
\end{tabular}

individual tautomers corrected for calculated abundances, the assignment of these stretching frequencies is performable. Further, regarding the band due to the $\mathrm{NH}$ stretching as a reference band, both the calculated $\mathrm{OH}$ stretching frequencies (3778 and $3699 \mathrm{~cm}^{-1}$ ) of $\mathbf{H 0 1}$ (24\% of the vapor phase) would be expected above the reference band wavenumber, whereas the $\mathrm{OH}$ stretchings of $\mathbf{K 0 2}\left(3418 \mathrm{~cm}^{-1}\right), \mathbf{K 0 3}$ $\left(3423 \mathrm{~cm}^{-1}\right)$, K04 $\left(3417 \mathrm{~cm}^{-1}\right)$, and $\mathrm{K06}\left(3421 \mathrm{~cm}^{-1}\right)$, contributing to the vapor phase for $67 \%$, would be expected at below the reference band. A further consideration regards the simplification of the overall infrared spectrum, due to overlaps of closely lying bands. On these accounts, the $\mathrm{OH}$ stretchings of K02, K03, K04, and $\mathrm{K06}$ would produce a single band centered at $3420 \pm 3 \mathrm{~cm}^{-1}$. In turn, the less abundant tautomers $\mathbf{K 0 7}$ and $\mathbf{K 0 9}$ (4.5\% of the vapor phase) are expected to give a band at $3522 \mathrm{~cm}^{-1}$ producing an overlap with the band of the $\mathrm{NH}$ stretching. However, the infrared signal due to these forms would be of thoroughly negligible intensity. It is therefore on these premises that the $\mathrm{OH}$ stretching due to the tautomers K02, K03, K04, and K06 could be identified in the broad peak measured at $3371 \mathrm{~cm}^{-1}$. At last H01, the only detectable hydroxy form is the only species which would originate two distinct bands, predicted at 3477 and $3551 \mathrm{~cm}^{-1}$. Thus, one $\mathrm{OH}$ stretching of $\mathrm{H01}$ would correspond to the band measured at 3566.2$3563.0 \mathrm{~cm}^{-1}$, whilst the other $\mathrm{OH}$ stretching calculated below the reference band could be identified with the band at $3498.7 \mathrm{~cm}^{-1}$. The FTIR spectrum measured in Ar matrix within 3800 and $3200 \mathrm{~cm}^{-1}$ is shown in Figure 3.

Another interesting region of the infrared spectrum to be considered is that of the $\mathrm{C}=\mathrm{O}$ and $\mathrm{C}=\mathrm{C}$ stretchings, which are characterizing vibrations of the infrared spectrum of the molecule. The $\mathrm{C}=\mathrm{C}$ bond is the typical feature of any hydroxy tautomer, and, bearing in mind the calculated population of the most stable tautomers at $380 \mathrm{~K}$, occurrence of this stretching vibration in the actual infrared spectrum would strongly confirm the presence of the hydroxy form H01. Both the $\mathrm{C}=\mathrm{O}$ and $\mathrm{C}=\mathrm{C}$ vibrations are strongly coupled between them and with other modes of the molecule (actually, potential energy distribution shows high vibrational coupling among all fundamental vibrations, except for the $\mathrm{NH}$ and 


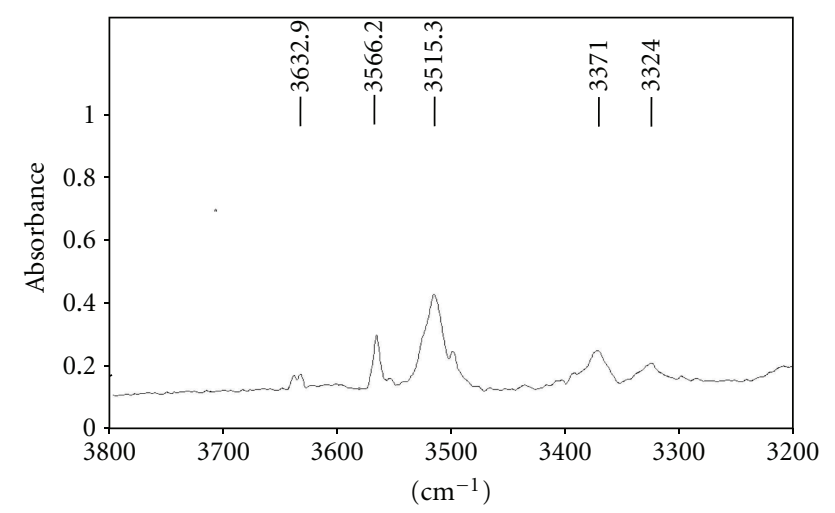

FIGURE 3: FTIR spectrum of IPA vapor isolated in argon matrix $\left(3800-3200 \mathrm{~cm}^{-1}\right)$.

$\mathrm{CH}$ stretchings). Also in this case, these vibrations show a valuable anharmonic character influencing both the location of these modes in the spectrum and related infrared intensity. Following the procedure described in this work for the $\mathrm{NH}$ and $\mathrm{OH}$ vibrations, calculated $\mathrm{C}=\mathrm{O}$ and $\mathrm{C}=\mathrm{C}$ stretching frequencies were scaled by 0.97 and 0.96 , respectively.

The $\mathrm{C}=\mathrm{O}$ stretching character of the calculated frequencies of the $1700-1800 \mathrm{~cm}^{-1}$ range easily emerges from internal mode analysis of the theoretical infrared spectra. These stretching vibrations produce the highest-intensity infrared bands of the spectrum, irrespective of the tautomer considered. Restricting the discussion to the most abundant vapourphase tautomers, within the harmonic approximation, the calculated $\mathrm{C}=\mathrm{O}$ stretchings always occur at higher frequencies than the $\mathrm{C}=\mathrm{C}$ stretching modes. Concerning the latter vibration, the band measured at $1610.8 \mathrm{~cm}^{-1}$ is attributed to the $\mathrm{C}=\mathrm{C}$ stretching of the $\mathrm{H01}$ tautomer (likely $\mathrm{H05}$ has no meaningful contribute to the infrared spectrum due to its very low abundance). The observation of the $\mathrm{C}=\mathrm{C}$ stretching frequency in the argon matrix spectrum valuably supports occurrence of $\mathrm{H01}$ in the vapour phase.

The calculations suggest that the $\mathrm{C}=\mathrm{O}$ stretching mode related to the $\mathrm{C}=\mathrm{O}$ bond interacting with the $\mathrm{OH}$ group occurs at the highest frequency value for K02, K03, K04, and K06 $\left(\sim 1784 \pm 4 \mathrm{~cm}^{-1}\right)$, whereas the same vibration for a weaker interaction of the $\mathrm{C}=\mathrm{O}$ bond with the $\mathrm{OH}$ group would originate bands at $1742 \pm 2 \mathrm{~cm}^{-1}$ (K07 and K09) and at $1737 \mathrm{~cm}^{-1}$ (K07 and $\mathbf{K 0 9}$ ). The remaining stretchings of K03, K04, and K06 are calculated at 1708, 1728, and $1713 \mathrm{~cm}^{-1}$, respectively. At last, the $\mathrm{C}=\mathrm{O}$ stretching vibration of $\mathrm{H01}$ would produce a valuable intensity band at $1693 \mathrm{~cm}^{-1}$, which is the highest intensity band in this region. The theoretical infrared pattern of the $\mathrm{C}=\mathrm{O}$ and $\mathrm{C}=\mathrm{C}$ vibrations of the most abundant tautomers is summarized in Table 2 and keeping into account all these results, the intense band measured at $1716.4 \mathrm{~cm}^{-1}$ is attributed to the $\mathrm{C}=\mathrm{O}$ stretching of the hydroxy form H01, the other high-intensity band measured at $1721.0 \mathrm{~cm}^{-1}$ would be therefore attributed to the $\mathrm{C}=\mathrm{O}$ stretching mode of $\mathrm{KO2}, \mathrm{K03}, \mathrm{K04}$, and $\mathrm{K06}$, and the band observed at $1796.4 \mathrm{~cm}^{-1}$ should be due to the highest frequency $\mathrm{C}=\mathrm{O}$ stretchings of $\mathrm{K07}$ and K09.
TABLE 3: Summary of some characterizing modes of the molecule (B3LYP/6-311++G** unscaled values).

\begin{tabular}{|c|c|c|c|c|c|c|}
\hline & $\delta \mathrm{C}-\mathrm{O}-\mathrm{H}$ & $\nu \mathrm{C}-\mathrm{O}-\mathrm{H}$ & $(\mathrm{C}-\mathrm{OH})$ tors & $\nu \mathrm{C}_{\alpha}-\mathrm{C}_{\beta}^{(\mathrm{a})}$ & $\delta_{\text {ip }} \mathrm{NH}$ & $\delta_{\mathrm{op}} \mathrm{NH}$ \\
\hline \multirow{2}{*}{ H01 } & 1338 & 1114 & 557 & & 1459 & 449 \\
\hline & 1310 & 1172 & 508 & & & \\
\hline K02 & 1375 & 1188 & 703 & 763 & 1447 & 412 \\
\hline K03 & 1384 & 1188 & 699 & 768 & 1446 & 403 \\
\hline K04 & 1355 & 1200 & 725 & 772 & 1448 & 398 \\
\hline K06 & 1373 & 1197 & 716 & 784 & 1450 & 403 \\
\hline K07 & 1370 & 1186 & 651 & 745 & 1445 & 429 \\
\hline K09 & 1372 & 1184 & 653 & 748 & 1447 & 417 \\
\hline \multirow{2}{*}{ H05 } & 1326 & 1058 & 563 & & 1454 & 449 \\
\hline & 1143 & 1091 & 644 & & & \\
\hline
\end{tabular}

(a) denotes the $\mathrm{C}_{\alpha} \mathrm{C}_{\beta}$ bond of the keto-carboxylic section of the $\mathrm{K}$ type species.

The remaining vibrations to be discussed are those involving the $\mathrm{C}-\mathrm{OH}$ bending and stretching vibrations, which are strongly coupled between them (see Table 3 ). The former vibrations, having high infrared intensity, are calculated within a narrow range, and consequently the resulting infrared pattern might be apparently simplified because closely lying bands are expected to overlap. The calculations suggest that all the abundant keto forms produce absorption lines at higher frequency $\left(1384-1355 \mathrm{~cm}^{-1}\right)$ than the only detectable hydroxy form $\mathrm{H01}\left(1338-1310 \mathrm{~cm}^{-1}\right)$. The frequencies computed within these ranges have large $\mathrm{C}-\mathrm{OH}$ bending contribution and are strongly coupled with other molecular vibrations. Among these frequencies, the theoretical ones 1375 and $1384 \mathrm{~cm}^{-1}$ belong to $\mathbf{K 0 2}$ and $\mathrm{KO3}$ (see Table 3) and those around $1370 \mathrm{~cm}^{-1}$ to $\mathbf{K 0 6}, \mathbf{K 0 7}$, and $\mathrm{K} 09$. According to the calculations the best correlation between calculated and observed frequencies should be the following one: $1368.1 \mathrm{~cm}^{-1}$ (K03), $1361.4 \mathrm{~cm}^{-1}$ (K02), $1358.8 \mathrm{~cm}^{-1}$ (K06, K07 and K09), and $1353.9 \mathrm{~cm}^{-1}$ (K04). At last, the bands measured at 1338.5 and $1332.0 \mathrm{~cm}^{-1}$ would be ascribed to the C-OH-bending vibrations of $\mathbf{H 0 1}$.

The most abundant hydroxy form H01 is also expected from the calculations to have two high-intensity infrared absorptions at 1404 and $1419 \mathrm{~cm}^{-1}$, which would correspond to the peaks measured at 1412.9 and $1427.6 \mathrm{~cm}^{-1}$. The bending of the $\mathrm{NH}$ group deservers particular care because this vibration would be expected to be confined within a narrow frequency range as it does not participate to any intramolecular interaction. Actually, this mode, strongly coupled with other vibrations of the molecule, is calculated at $1447 \pm 3 \mathrm{~cm}^{-1}$ for all the keto species and at $1456 \pm 2 \mathrm{~cm}^{-1}$ for H01 and H05. According to the calculations, this vibration would be associated with low infrared intensity bands. Keeping into account these considerations, as well as the calculated vapor-phase abundances, the frequency $1457.8 \mathrm{~cm}^{-1}$ absorption appears to be the best candidate for the in-plane $\mathrm{NH}$ bending, likely for all the $\mathrm{K}$ and $\mathrm{H01}$ species. The theoretical spectrum of $\mathrm{H01}$ would show high-intensity bands around $1170 \mathrm{~cm}^{-1}$, which would be another typical feature of this hydroxy form. 
Calculations do not suggest high intensity bands in this range for any keto form of the molecule. For this reason, the observed band at $1155.7 \mathrm{~cm}^{-1}$ is likely to be due to the $\mathrm{C}-\mathrm{OH}$ stretching of the most abundant hydroxy form, being the other $\mathrm{C}-\mathrm{OH}$ stretching assigned to the band observed at $1132.1 \mathrm{~cm}^{-1}$ (expected value $1114 \mathrm{~cm}^{-1}$ ).

The keto forms would show relatively high infrared bands around 1100 and $1000 \mathrm{~cm}^{-1}$. More in detail, relying on the theoretical infrared band intensities, $\mathrm{H01}$ and H05, which is however quite negligible in vapor phase, they are the species having the highest infrared band intensity values in this range. However, due to several overlaps among bands of the different tautomers, the overall infrared pattern of this region is a very complex one. From a vibrational point of view, some of these bands have a high $\mathrm{C}-\mathrm{OH}$ stretching character, as P.E.D. analysis suggests. It is therefore on this ground that the $\mathrm{C}-\mathrm{OH}$ stretching frequency observed at $1112.2 \mathrm{~cm}^{-1}$ was attributed to that vibrational mode of the most abundant $\mathrm{K02}, \mathrm{K03}$, and K04 fforms. The FTIR spectrum of IPA isolated in Ar matrix is shown in Figure 4 within the range 2000$1200 \mathrm{~cm}^{-1}$.

After discussing the bands characterizing the infrared spectrum of IPA, we shall review other bands observed in argon matrix spectrum which, however, are of less interest.

\section{Indole Carbon-Hydrogen Modes}

The $\mathrm{CH}$ stretchings, all of negligible intensities, occur for all the hydroxy and keto species around $3000 \mathrm{~cm}^{-1}$. As expected, these modes are hardly observed in the infrared spectrum of matrix-isolated molecules, whilst a single weak band is detected in the DRIFT spectrum of solid IPA at $3059 \mathrm{~cm}^{-1}$ (see later in this work). There is no clear evidence of further bands in this high-frequency region of the infrared spectrum, except a very weak band at $2931 \mathrm{~cm}^{-1}$ due to $\mathrm{CH}$ stretching modes of the pyruvic fragment. On the other hand, calculations show quite low intensity of the infrared bands of all the $\mathrm{CH}$ stretching vibrations of this molecular system. On comparison of the present experimental data with the most significant ones available for closely related species [12, 13], four bands measured at 1492.8, 1187, 1149.8, and $1093.0 \mathrm{~cm}^{-1}$ can be associated to in-plane $\mathrm{CH}$ bendings. The out-of-plane $\mathrm{CH}$ bendings, all of negligible IR band intensity, are predicted in the spectral range $1000-850 \mathrm{~cm}^{-1}$, in agreement with the calculations which will be examined later in the work. Experimentally, a single weak band due to these vibrations is observed at $1013.2 \mathrm{~cm}^{-1}$.

\section{Indole Ring Carbon-Carbon Modes}

The bands at 1690 and $1619 \mathrm{~cm}^{-1}$ are assigned to carboncarbon stretching modes of the benzene ring together with a medium intensity band observed at about $1378 \mathrm{~cm}^{-1}$. In addition to that, bands at $1535.0,1223.5 \mathrm{~cm}^{-1}$, and a shoulder approximately located at $1275 \mathrm{~cm}^{-1}$, having, according to the calculations, a valuable contribution of carbon-carbon stretching of the pyrrole ring, were measured in the spectrum of single molecule. As a further support, features at 1619.0

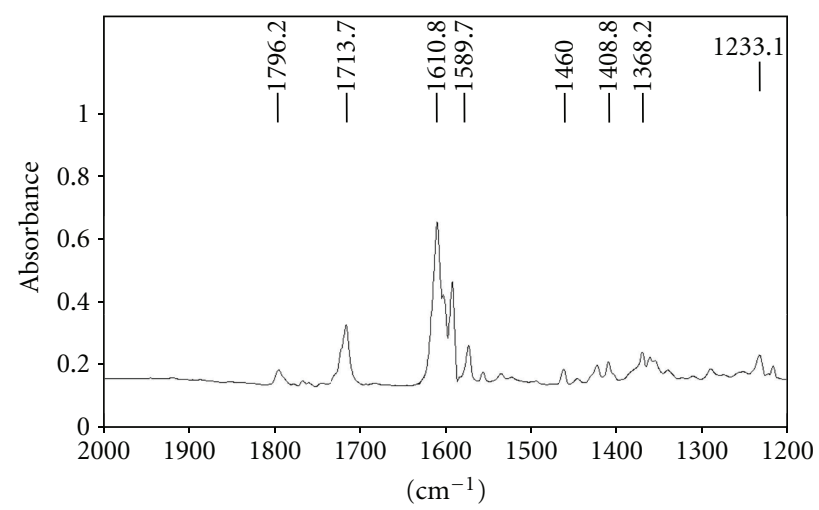

FIGURE 4: FTIR spectrum of IPA vapor isolated in argon matrix $\left(2000-1200 \mathrm{~cm}^{-1}\right)$.

and $1535.0 \mathrm{~cm}^{-1}$ show excellent agreement with the corresponding vibrations predicted for tryptophan and benzene and pyrrole rings, respectively, at 1619 and $1531 \mathrm{~cm}^{-1}$ [10]. Previous spectroscopic analysis of monomeric indole [10] places a carbon-carbon stretching of the pyrrole ring at $1206 \mathrm{~cm}^{-1}$, confidently corresponding to the peak at $1212.8 \mathrm{~cm}^{-1}$ detected in this work.

\section{Indole Nitrogen-Hydrogen Bands}

The in-plane NH-bending mode of the indole fragment of the molecule deserves some consideration. The medium intense peak observed at $1457.8 \mathrm{~cm}^{-1}$ in matrix-isolated spectra matches the theoretical predictions reasonably-but, according to the theoretical treatment, the in-plane $\mathrm{NH}$ bending contributes in different extent to several calculated vibrations detected experimentally for the isolated molecule at $1523.0,1460.0,1223.0$, and $1098 \mathrm{~cm}^{-1}$. The last mode would match quite well the frequency value of corresponding mode of monomeric indole in solid state at $1085 \mathrm{~cm}^{-1}$ [10]. However, P.E.D. analysis would suggest that the major contribution to this vibration should arise from bands calculated and observed at $\sim 1400 \mathrm{~cm}^{-1}$. Under this aspect, the present assignment does not agree with that reported for tryptophan [13] for this mode. The out-of-plane NH bending observed at $418.5 \mathrm{~cm}^{-1}$ is in excellent agreement with the band reported at $403 \mathrm{~cm}^{-1}$ for monomeric indole [10] in solid state.

\section{Indole Deformation Modes}

A number of in-plane and out-of-plane modes are predicted resulting from deformation of the whole indole molecule however, only few of them were observed experimentally, that is, peaks at $\sim 1044,752,656, \sim 604$, and $514 \mathrm{~cm}^{-1}$ are assigned to in-plane modes, and peaks at 768.2 and $739.9 \mathrm{~cm}^{-1}$ are attributed to out-of-plane vibrations (see Figure 5). Comparison with previous experimental and theoretical data available on the analogous molecules indole [10] and tryptophan [13] provides some support to the proposed assignment. A band at $602 \mathrm{~cm}^{-1}$ has been ascribed to the in-plane ring deformation of monomeric indole [10], likely 


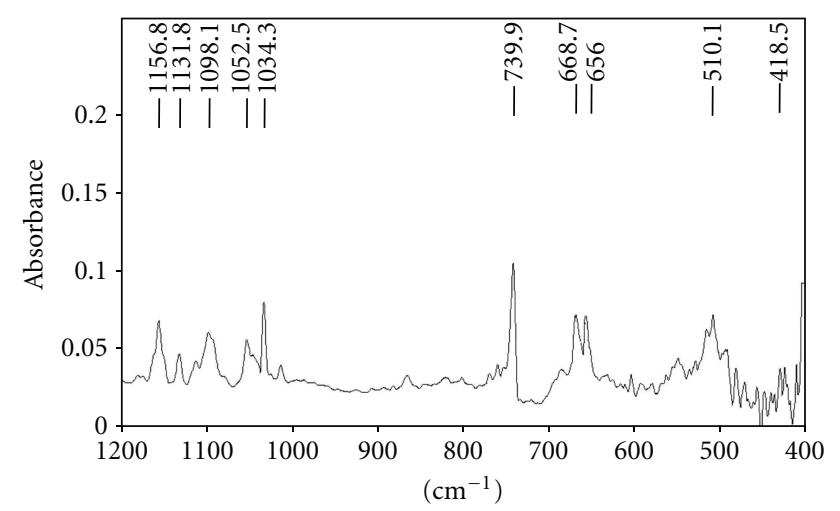

FIGURE 5: FTIR spectrum of IPA vapor isolated in argon matrix $\left(1200-400 \mathrm{~cm}^{-1}\right)$.

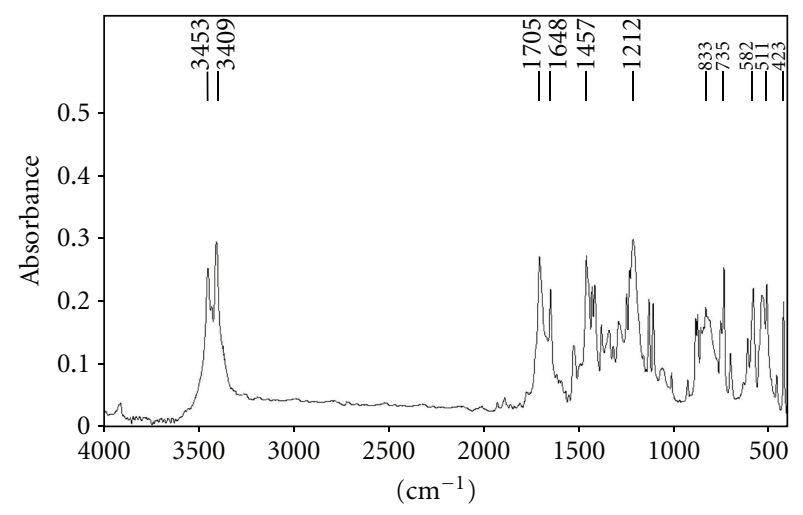

FIgURE 6: DRIFT spectrum of IPA $\left(4000-400 \mathrm{~cm}^{-1}\right)$.

corresponding to the broad, weak bands at about $604 \mathrm{~cm}^{-1}$ of IPA molecule while features at 529 and $640 \mathrm{~cm}^{-1}$ assigned to ring deformation of isolated tryptophan [13] show good agreement with features at 514 and $656 \mathrm{~cm}^{-1}$ of this work.

The agreement between experimental and calculated frequencies of these modes is good for all the structures examined however, the high intensity of bands at 740 and $656 \mathrm{~cm}^{-1}$ is not reproduced in calculations.

\section{Chain Group Modes}

As observed for the indolic group, $\mathrm{CH}$-stretching modes, predicted in the spectral range $3170-3180 \mathrm{~cm}^{-1}$, are too weak to be detected. The in-plane and out-of-plane $\mathrm{CH}$-bending modes of IPA are individuated at 1421 and $757.5 \mathrm{~cm}^{-1}$. The observation of a band at $1424 \mathrm{~cm}^{-1}$ in argon isolated pyruvic acid [11], attributed to asymmetric bending $\mathrm{CH}$ mode, supports the assignment proposed for the former band. A very weak out-of-plane bending mode predicted in the spectral interval $888-923 \mathrm{~cm}^{-1}$ is not observed in the matrix spectra.

\section{DRIFT Spectrum}

The spectroscopic behavior of IPA in $\mathrm{KBr}$ pellets and in solution has been studied far ago [15]. In the previous papers, indole-3-pyruvic acid is reported to be treated with organic solvents of different acid-basic character in order to characterize the keto-enol equilibrium. A semiquantitative evaluation of the relative abundance of tautomers was given by the intensity ratio of two diagnostic bands, the carbon-carbon double bond stretching mode, around $1640 \mathrm{~cm}^{-1}$ and the $\mathrm{C}=\mathrm{O}$ stretching mode around $1720 \mathrm{~cm}^{-1}$ [15].

For sake of comparison, the spectrum of IPA dispersed in $\mathrm{KBr}$ was remeasured employing the Diffuse Reflectance Fourier Transform Infrared spectroscopy/(DRIFT) technique and compared to previous results obtained on $\mathrm{KBr}$ pellets. The spectral interval of interest $\left(4000-400 \mathrm{~cm}^{-1}\right)$ is reported in Figure 6. In spite of the different technique employed, the spectrum matches perfectly literature results confirming the huge predominance of the hydroxy form of crystalline IPA. The X-Ray diffraction study [7] is of particular interest because the hydroxy tautomer present in the crystal is reported to be $\mathbf{H O 1}$ held together by two types of intermolecular hydrogen bonds occurring between the carboxy groups and between the hydroxy and carboxy groups in the unitary cell [7]. An attempt to simulate the theoretical spectrum of the molecule in the crystal was first made by optimizing its equilibrium geometry employing the B3PW91 and B3LYP density functionals with the $6-311++\mathrm{G}^{* *}$ basis sets. The B3PW91/6-311++G** calculations were found to agree with the crystallographic result better that the B3LYP/6$311++\mathrm{G}^{* *}$ level, and for this reason the B3PW01 density functional was adopted for this study. However, the vibrational frequencies of this structure consisting of four interacting molecules of $\mathbf{H 0 1}$ type could not be done with the 6$311++\mathrm{G}^{* *}$ basis set because CPU time requirements would have been prohibitive. The DFT simulation of the spectrum of crystalline IPA was then based on CPCM calculations accomplished on the hydroxyl form $\mathrm{H01}$ in $\mathrm{KBr}$ (dielectric constant 4.88) [12], but calculations cannot be regarded as satisfactory enough. A further improvement was obtained when one molecule of $\mathbf{H 0 1}$ type was surrounded by suitable fragments reproducing the intermolecular interactions present in the crystal. In particular, the simulation of the infrared spectrum of H01 in the crystal provided the actual frequency shifts of the $\mathrm{NH}$ and $\mathrm{OH}$ stretching and of the $\mathrm{C}-\mathrm{OH}$ bendings. The calculations and P.E.D. analysis place the in-plane NH-bending at $1465 \mathrm{~cm}^{-1}$ corresponding to the measured band ay $1427.6 \mathrm{~cm}^{-1}$, close to the value measured in argon matrix. By the way, one has to observe that the inplane and out-of-plane NH-bending modes of indole dimers were individuated in solid state at 1120 and $500 \mathrm{~cm}^{-1}$, respectively, and the large frequency shift is ascribed to $\mathrm{NH} \cdots \pi$ interaction [10]. However, our calculations would not agree with the assignment proposed in literature for the in-plane and out-of-plane $\mathrm{NH}$-bending modes and according to us, the assignment of the bands of the DRIFT spectrum observed at 1129.4 and $516.0 \mathrm{~cm}^{-1}$ is that reported in Table 4 .

\section{Conclusion}

The infrared spectrum of the single molecule of the indole3-pyruvic acid (IPA) was obtained using the matrix isolation 
TABLE 4: Theoretical B3PW91/6-311++G** frequencies $\left(\mathrm{cm}^{-1}\right)$ of $\mathrm{H01}$ tautomer calculated for the free molecule and the molecule in its crystal phase.

\begin{tabular}{|c|c|c|c|}
\hline Free molecule & Crystal molecule & DRIFT & Approximate description \\
\hline 3805 & 3688 & 3433 & $\nu \mathrm{OH}$ \\
\hline 3704 & 3498 & 3411 & $\nu \mathrm{OH}$ \\
\hline 3686 & 3682 & 3453 & $\nu \mathrm{NH}$ \\
\hline 3288 & 3280 & & $v \mathrm{CH}$ \\
\hline 3216 & 3225 & & $\nu \mathrm{CH}$ \\
\hline 3202 & 3203 & & $\nu \mathrm{CH}$ \\
\hline 3191 & 3193 & & $\nu \mathrm{CH}$ \\
\hline 3181 & 3183 & & $\nu \mathrm{CH}$ \\
\hline 3174 & 3176 & & $\nu \mathrm{CH}$ \\
\hline 1758 & 1737 & 1704.7 & $\nu \mathrm{C}=\mathrm{O} / \nu \mathrm{C}=\mathrm{C}$ \\
\hline 1712 & 1705 & 1648.1 & $\nu \mathrm{C}=\mathrm{C} / \nu \mathrm{C}=\mathrm{O}$ \\
\hline 1672 & 1672 & & $\nu$ Ring \\
\hline 1630 & 1629 & & $\nu$ Ring \\
\hline 1570 & 1563 & 1523.7 & $\nu \operatorname{Ring} / \delta_{\text {ip }} \mathrm{NH}$ \\
\hline 1529 & 1529 & & $\nu$ Ring $/ \delta_{\text {ip }} \mathrm{NH} / \delta_{\text {ip }} \mathrm{CH}$ \\
\hline 1489 & 1488 & & $\nu \operatorname{Ring} / \delta_{\text {ip }} \mathrm{CH}$ \\
\hline 1471 & 1465 & 1457 & $\delta_{\mathrm{ip}} \mathrm{NH} / \nu \operatorname{Ring} / \delta_{\mathrm{ip}} \mathrm{COH} / \delta_{\mathrm{ip}} \mathrm{CH}$ \\
\hline 1435 & 1443 & 1427.6 & $\delta_{\text {ip }} \mathrm{CH} / \delta_{\mathrm{ip}} \mathrm{COH}$ \\
\hline 1414 & 1414 & 1421.9 & $\delta_{\mathrm{ip}} \mathrm{CH} / \nu \mathrm{Ring} / \delta_{\mathrm{ip}} \mathrm{COH} / \delta_{\mathrm{ip}} \mathrm{NH}$ \\
\hline 1388 & 1388 & 1378.9 & $\delta_{\mathrm{ip}} \mathrm{CH} / \nu \operatorname{Ring} / \delta_{\mathrm{ip}} \mathrm{NH} / \delta_{\mathrm{ip}} \mathrm{COH}$ \\
\hline 1349 & 1349 & & $\nu$ Ring $/ \delta_{\text {ip }} \mathrm{CH} / \delta_{\text {ip }} \mathrm{COH}$ \\
\hline 1346 & 1337 & 1336.9 & $\delta_{\mathrm{ip}} \mathrm{COH} / \delta_{\mathrm{ip}} \mathrm{CH} / \nu \operatorname{Ring} / \nu \mathrm{COH}$ \\
\hline 1313 & 1288 & 1289.7 & $\delta_{\text {ip }} \mathrm{COH} / \nu \operatorname{Ring} / \delta_{\text {ip }} \mathrm{CH} / \nu \mathrm{COH}$ \\
\hline 1268 & 1267 & & $\delta_{\mathrm{ip}} \mathrm{CH} / \delta_{\mathrm{ip}} \mathrm{NH} / \nu \operatorname{Ring}$ \\
\hline 1257 & 1254 & 1245.8 & $\delta_{\mathrm{ip}} \mathrm{CH} / \nu \operatorname{Ring} / \delta_{\mathrm{ip}} \mathrm{COH}$ \\
\hline 1183 & 1233 & 1212.8 & $\nu \mathrm{COH} / \delta_{\mathrm{ip}} \mathrm{COH} \nu \mathrm{CC} / \delta_{\mathrm{ip}} \mathrm{CH}$ \\
\hline 1174 & 1175 & 1129.4 & $\delta_{\mathrm{ip}} \mathrm{CH} / \delta_{\mathrm{ip}} \mathrm{COH} / \nu \operatorname{Ring}$ \\
\hline 1154 & 1154 & 1106.7 & $\delta_{\mathrm{ip}} \mathrm{CH} / \nu$ Ring \\
\hline 1130 & 1143 & & $\nu \mathrm{COH} / \delta_{\mathrm{ip}} \mathrm{CH} / \delta_{\mathrm{ip}} \mathrm{NH}$ \\
\hline 1122 & 1123 & & $\delta_{\text {ip }} \mathrm{CH} / \delta_{\text {ip }} \mathrm{NH} / \nu \operatorname{Ring} / \nu \mathrm{COH}$ \\
\hline 1085 & 1080 & 1060.7 & $\nu$ Ring $/ \delta_{\text {ip }}$ Ring \\
\hline 1040 & 1039 & 1010.1 & $\nu$ Ring $/ \delta_{\text {ip }}$ Ring \\
\hline 972 & 977 & 925.5 & $\delta_{\mathrm{op}} \mathrm{CH}$ \\
\hline 937 & 940 & & $\delta_{\mathrm{op}} \mathrm{CH}$ \\
\hline 892 & 903 & & $\delta_{\text {ip }}$ Ring \\
\hline 884 & 887 & 884.2 & $\delta_{\text {ip }}$ Ring \\
\hline 888 & 879 & 874.6 & $\delta_{\mathrm{op}} \mathrm{CH}$ \\
\hline 853 & 853 & 858.4 & $\delta_{\mathrm{op}} \mathrm{CH}$ \\
\hline 839 & 841 & 832.6 & $\delta_{\mathrm{op}} \mathrm{CH}$ \\
\hline 818 & 821 & & $\delta_{\text {ip }}$ Ring \\
\hline 773 & 779 & 755.7 & $\delta_{\mathrm{op}} \operatorname{Ring}$ \\
\hline 767 & 768 & 750.3 & $\delta_{\text {ip }}$ Ring \\
\hline 751 & 751 & & $\delta_{\mathrm{op}} \mathrm{CH}$ \\
\hline 678 & 660 & 702.3 & $\delta_{\text {ip }}$ Ring \\
\hline 646 & 627 & 633.0 & $\delta_{\text {op }}$ Ring \\
\hline 612 & 610 & 612.1 & $\delta_{\text {ip }}$ Ring \\
\hline 586 & 585 & 580.9 & $\delta_{\mathrm{op}} \mathrm{Ring} / \delta_{\mathrm{op}} \mathrm{NH} / \delta_{\mathrm{op}} \mathrm{COH}$ \\
\hline 561 & 562 & & $\delta_{\text {ip }}$ Ring \\
\hline 527 & 540 & 537 & $\delta_{\mathrm{op}} \mathrm{COH}$ \\
\hline 513 & 528 & 530 & $\delta_{\text {ip }} \operatorname{Ring}$ \\
\hline
\end{tabular}


TABle 4: Continued.

\begin{tabular}{lccc}
\hline Free molecule & Crystal molecule & DRIFT & Approximate description \\
\hline 488 & 526 & 516.0 & $\delta_{\text {op }}$ COH \\
464 & 466 & 459.0 & $\delta_{\text {ip }}$ Ring \\
462 & 462 & 422.3 & $\delta_{\text {op }} \mathrm{NH}$ \\
\hline
\end{tabular}

TABle 5: Assignment of the measured Ar-matrix frequencies $\left(\mathrm{cm}^{-1}\right)$.

\begin{tabular}{|c|c|c|c|}
\hline Exp. & Approximate description ${ }^{(a)}$ & Exp. & Approximate description (a) \\
\hline $3566.2-3563.0$ & vOH H01 & 1353.9 & $\delta \mathrm{C}-\mathrm{OH}$ K04 \\
\hline 3514.5 & $v \mathrm{NH}$ & 1338.5 & $\delta \mathrm{C}-\mathrm{OH} \mathbf{H 0 1}$ \\
\hline \multirow{2}{*}{3498.7} & \multirow{2}{*}{ ขOH H01 } & 1333.5 & $\delta \mathrm{C}-\mathrm{OH} \mathbf{H 0 1}$ \\
\hline & & 1332.0 & $\delta \mathrm{C}-\mathrm{OH} \mathrm{H} 01$ \\
\hline 3371.0 & ขOH K02 K03 К04 K06 & 1309.5 & \\
\hline 2931 & $\nu \mathrm{CH}$ & 1289.4 & $\nu \mathrm{Ring} / \delta_{\mathrm{ip}} \mathrm{CH} / \delta_{\mathrm{ip}} \mathrm{C}-\mathrm{OH}$ \\
\hline \multirow{2}{*}{1796.4} & \multirow{2}{*}{$\nu \mathrm{C}=\mathrm{O}$ K07 K09 } & 1275 & $\nu$ Ring $/ \delta_{\text {ip }} \mathrm{CH}$ \\
\hline & & $1233.5-1232.9$ & $\nu$ Ring \\
\hline 1721.0 & \multicolumn{2}{|l|}{$\nu \mathrm{C}=\mathrm{O}$ K02 K03 K04 K06 } & \\
\hline 1716.4 & \multirow[t]{2}{*}{$\nu \mathrm{C}=\mathrm{O} \mathrm{H} 01$} & 1212.8 & $\nu$ Ring \\
\hline 1713.7 & & $1187-1181$ & $\delta_{\mathrm{ip}} \mathrm{CH}$ \\
\hline 1690.0 & $v$ Ring & $1169-1163$ & \\
\hline 1619.0 & $\nu$ Ring & 1155.7 & $\nu \mathrm{C}-\mathrm{OH}$ H01 \\
\hline 1610.8 & \multirow[t]{2}{*}{$\nu \mathrm{C}=\mathrm{C} \mathbf{H} 01$} & 1149.8 & $\delta_{\text {ip }} \mathrm{CH}$ \\
\hline 1602.0 & & 1135 & $\nu \mathrm{Ring} / \nu \mathrm{C}-\mathrm{OH} / \delta_{\mathrm{ip}} \mathrm{C}-\mathrm{OH}$ \\
\hline 1598.3 & $\nu$ Ring $/ \delta_{\text {ip }} \mathrm{CH}$ & 1132.1 & vC-OH H01 \\
\hline 1590.3 & $\nu$ Ring $/ \delta_{\text {ip }} \mathrm{CH}$ & 1112.2 & vC-OH K02 K03 K04 \\
\hline 1535.0 & $\nu$ Ring & 1103.7 & \\
\hline 1523.0 & & 1097.6 & $\delta_{\text {ip }} \mathrm{CH} / \delta_{\text {ip }} \mathrm{NH} / \nu$ Ring \\
\hline 1492.8 & $\delta_{\text {ip }} \mathrm{CH} / \nu$ Ring & 1093.0 & $\delta_{\mathrm{ip}} \mathrm{CH} / \nu \mathrm{C}-\mathrm{OH}$ \\
\hline 1460.0 & $\nu \operatorname{Ring} / \delta_{\text {ip }} \mathrm{NH} / \delta_{\text {ip }} \mathrm{CH}$ & 1044 & $\delta_{\mathrm{ip}} \operatorname{Ring}$ \\
\hline 1457.8 & $\delta_{\text {ip }} \mathrm{NH}$ & 1044 & $\delta_{\text {ip }}$ Ring \\
\hline 1444.6 & $\delta_{\text {ip }} \mathrm{NH}$ & $1055.1-1052.4$ & \\
\hline 1427.6 & $\delta_{\mathrm{ip}} \mathrm{CH} / \nu \mathrm{C}-\mathrm{OH} \mathbf{H} 01$ & 1033.5 & $\delta_{\text {ip }} \operatorname{def}^{(b)}$ \\
\hline 1421 & $\delta_{\text {ip }} \mathrm{CH} / \nu \mathrm{C}-\mathrm{OH}$ & & \\
\hline 1412.9 & $\delta_{\text {ip }} \mathrm{CH} / \nu \mathrm{C}-\mathrm{OH} \mathbf{H 0 1}$ & & \\
\hline \multirow{2}{*}{1408.8} & \multirow{2}{*}{$\nu$ Ring $/ \delta_{\text {ip }} \mathrm{C}-\mathrm{OH}$} & 1013.2 & $\delta_{\text {ip }} \mathrm{CH}$ \\
\hline & & 866.2 & $\delta_{\text {ip }} \operatorname{def}^{(b)}$ \\
\hline 1378 & $\nu$ Ring & 768.2 & $\delta_{\text {op }}$ Ring \\
\hline 1368.1 & $\delta \mathrm{C}-\mathrm{OH}$ K03 & 757.5 & $\delta_{\text {ip }} \mathrm{CH}$ \\
\hline \multirow[t]{3}{*}{1361.4} & $\delta \mathrm{C}-\mathrm{OH}$ K02 & 752 & $\delta_{\text {ip }}$ Ring \\
\hline & & 739.9 & $\delta_{\text {op }} \operatorname{def}^{(\mathrm{b})}$ \\
\hline & & 656 & $\delta_{\text {ip }} \operatorname{Ring} / \delta_{\text {ip }} \operatorname{def}^{(\mathrm{b})}$ \\
\hline \multirow[t]{3}{*}{1358.8} & $\delta \mathrm{C}-\mathrm{OH}$ K06 К07 K09 & 604 & $\delta_{\text {ip }} \operatorname{Ring} / \delta_{\text {ip }} \operatorname{def}^{(\mathrm{b})}$ \\
\hline & & 514 & $\delta_{\text {ip }}$ Ring \\
\hline & & 418.5 & $\delta_{\mathrm{op}} \mathrm{NH}$ \\
\hline
\end{tabular}

(a) see text for details.

(b) in-plane or out-of-plane molecular deformation.

technique. The assignment of the experimental frequencies measured in argon matrix at $12 \mathrm{~K}$ was based on the conclusions of density functional and P.E.D. calculations accomplished for several hydroxy and keto structures of the molecule having, at least most of them, comparable stability and infrared pattern. This assignment of most of the observed bands measured in low-temperature Ar matrix is reported in Table 5. An accurate comparison between the theoretical and experimental IR spectroscopy data, as well as the results of previous studies on the similar species such as tryptophane, indole and pyruvic acid, suggests, within the limitations of the experimental and theoretical approaches, that one is able 
to characterize some distinctive vibrations of the most abundant tautomers by means of infrared spectroscopy coupled with matrix isolation method.

\section{References}

[1] M. S. El-Abyad, M. A. El-Sayed, A.-R. El-Shanshoury, and M. Farid, "Optimization of culture conditions for indole-3-pyruvic acid production by Streptomyces griseoflavus," Canadian Journal of Microbiology, vol. 40, no. 9, pp. 754-760, 1994.

[2] J. Koga, K. Syono, T. Ichikawa, and T. Adachi, "Involvement of L-tryptophan aminotransferase in indole-3-acetic acid biosynthesis in Enterobacter cloacae," Biochimica et Biophysica Acta, vol. 1209, no. 2, pp. 241-247, 1994.

[3] M. N. Perkins and T. W. Stone, "Actions of kynurenic acid and quinolinic acid in the rat hippocampus in vivo," Experimental Neurology, vol. 88, no. 3, pp. 570-579, 1985.

[4] V. Politi, M. V. Lavaggi, G. Di Stazio, and A. Margonelli, "Indole-3-pyruvic acid as a direct precursor of kynurenic acid," Advances in Experimental Medicine and Biology, vol. 294, pp. 515-518, 1991.

[5] V. Politi, S. D’Alessio, G. Di Stazio, and G. De Luca, "Antioxidant properties of indole-3-pyruvic acid," Advances in Experimental Medicine and Biology, vol. 398, pp. 291-298, 1996.

[6] B. Bartolini, C. Corniello, A. Sella, F. Somma, and V. Politi, "The enol tautomer of indole-3-pyruvic acid as a biological switch in stress responses," Advances in Experimental Medicine and Biology, vol. 527, pp. 601-608, 2003.

[7] N. Okabe and Y. Adachi, "2-Hydroxy-3-(1H-indol-3-yl)propenoic acid," Acta Crystallographica Section C, vol. 54, no. 9, pp. 1330-1331, 1998.

[8] G. Nazario and K. Schwarz, "Infrared spectra of indolepyruvic acid. Study of the keto-enol equilibrium in different organic solvents," Archives of Biochemistry and Biophysics, vol. 123, no. 3, pp. 457-461, 1968.

[9] J. Bai, X. Liang, Y. H. Liu, Y. Zhu, and D. M. Lubman, "Characterization of two new matrices for matrix-assisted laser desorption/ionization mass spectrometry," Rapid Communications in Mass Spectrometry, vol. 10, no. 7, pp. 839-844, 1996.

[10] R. Barraza, M. Campos-Vallette, K. Figueroa, V. Manríquez, and V. C. Vargas, "Hydrogen bond effect on the molecular vibrations of indole," Spectrochimica Acta Part A, vol. 46, no. 9, pp. 1375-1380, 1990.

[11] I. D. Reva, S. G. Stepanian, L. Adamowicz, and R. Fausto, "Combined FTIR matrix isolation and Ab initio studies of pyruvic acid: proof for existence of the second conformer," Journal of Physical Chemistry A, vol. 105, no. 19, pp. 47734780, 2001.

[12] X. Cao and G. Fischer, "Infrared spectral, structural, and conformational studies of zwitterionic L-tryptophan," Journal of Physical Chemistry A, vol. 103, no. 48, pp. 9995-10003, 1999.

[13] A. Kaczor, I. D. Reva, L. M. Proniewicz, and R. Fausto, "Matrix-isolated monomeric tryptophan: electrostatic interactions as nontrivial factors stabilizing conformers," Journal of Physical Chemistry A, vol. 111, no. 15, pp. 2957-2965, 2007.

[14] M. J. Frisch, G. W. Trucks, H. B. Schlegel et al., Gaussian 03, Revision C.02, Gaussian, Wallingford, Conn, USA, 2004.

[15] G. Schaftenaar and J. H. Noordik, "Molden: a pre- and postprocessing program for molecular and electronic structures," Journal of Computer-Aided Molecular Design, vol. 14, no. 2, pp. 123-134, 2000.

[16] M. H. Jamroz, Vibrational Energy Distribution Analysis: VEDA 4 Program, Warsaw, Poland, 2004.
[17] A. Kaczor, I. D. Reva, L. M. Proniewicz, and R. Fausto, "Importance of entropy in the conformational equilibrium of phenylalanine: a matrix-isolation infrared spectroscopy and density functional theory study," Journal of Physical Chemistry A, vol. 110, no. 7, pp. 2360-2370, 2006.

[18] T. D. Klots and W. B. Collier, "Heteroatom derivatives of indene Part 3. Vibrational spectra of benzoxazole, benzofuran, and indole," Spectrochimica Acta Part A, vol. 51, no. 8, pp. 1291-1316, 1995. 


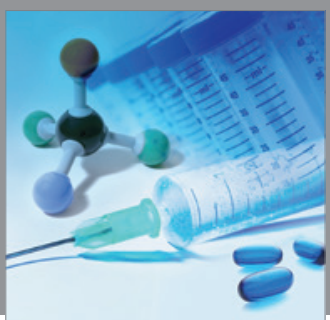

International Journal of

Medicinal Chemistry

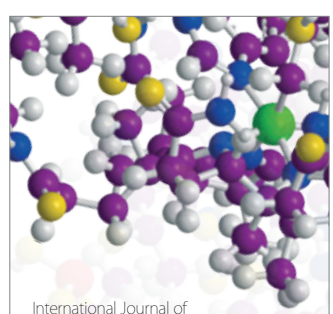

Carbohydrate Chemistry

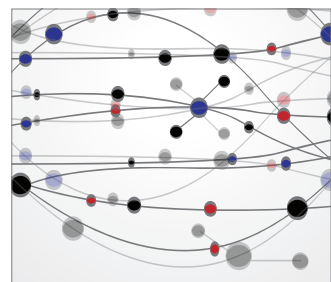

The Scientific World Journal
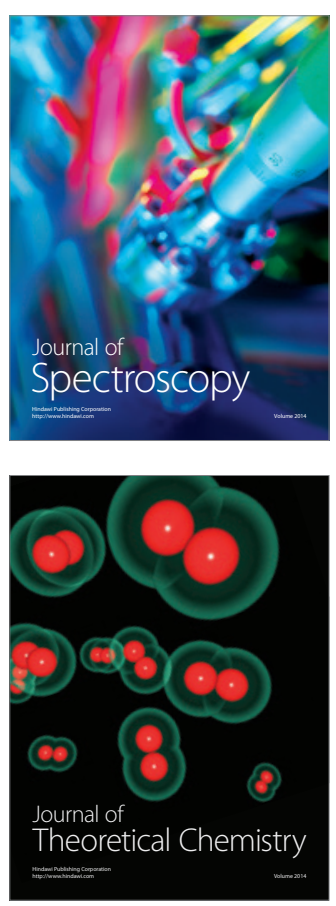
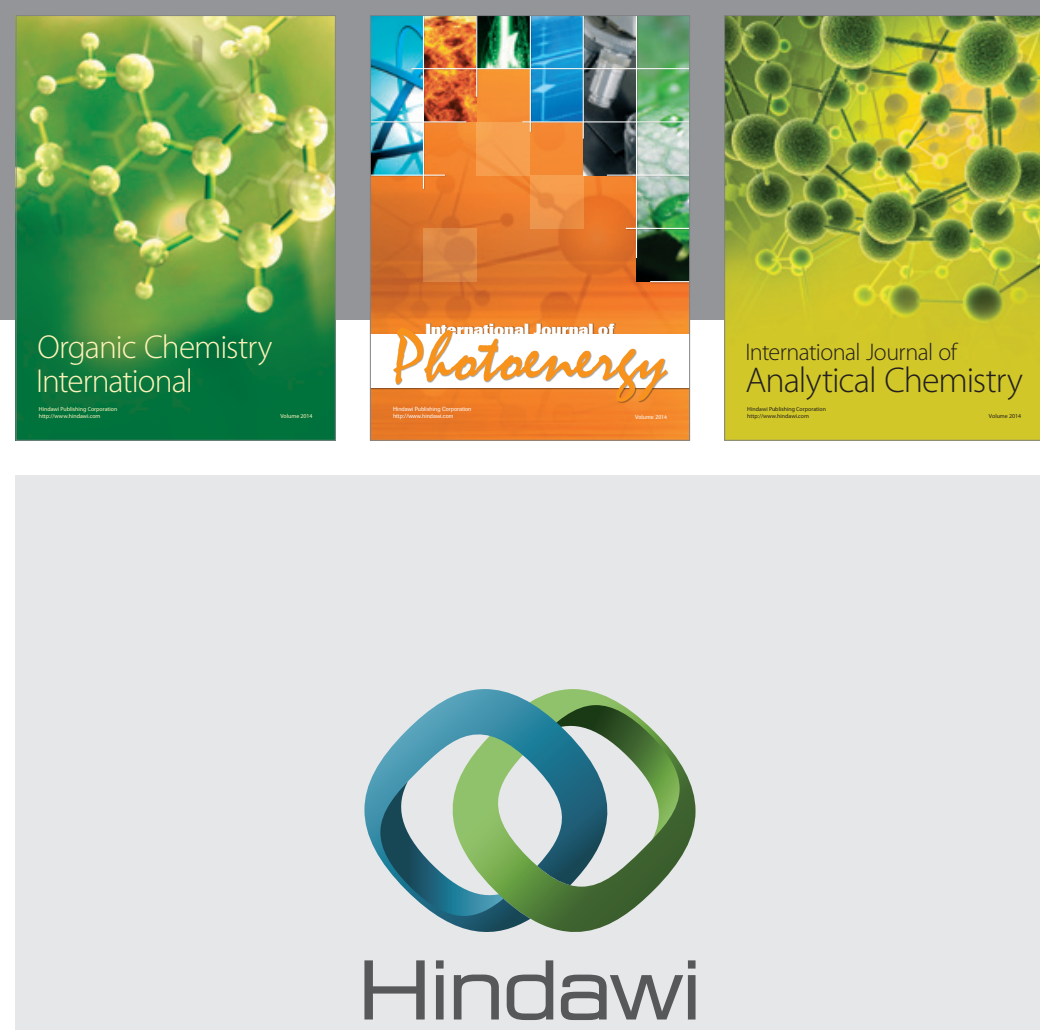

Submit your manuscripts at

http://www.hindawi.com
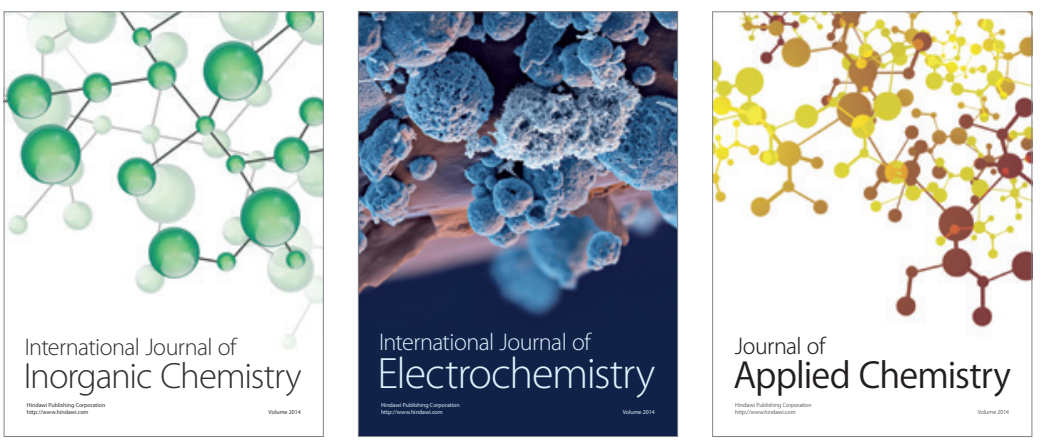

Journal of

Applied Chemistry
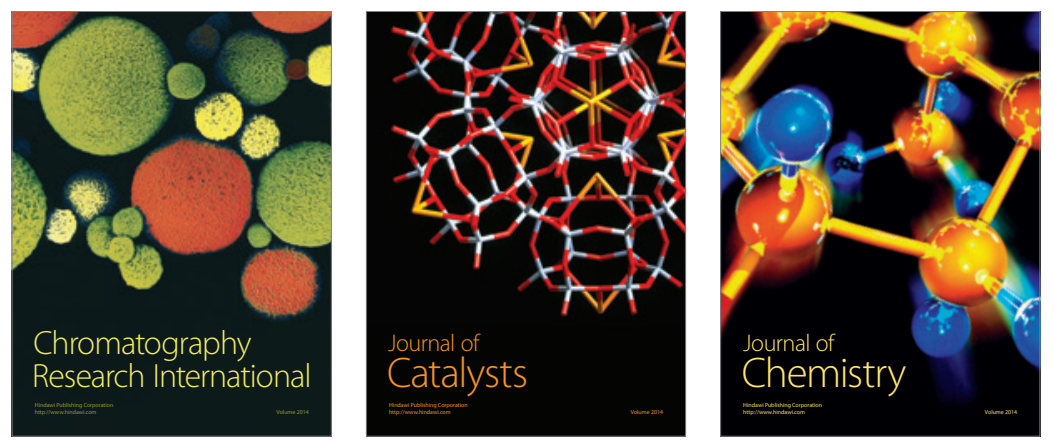
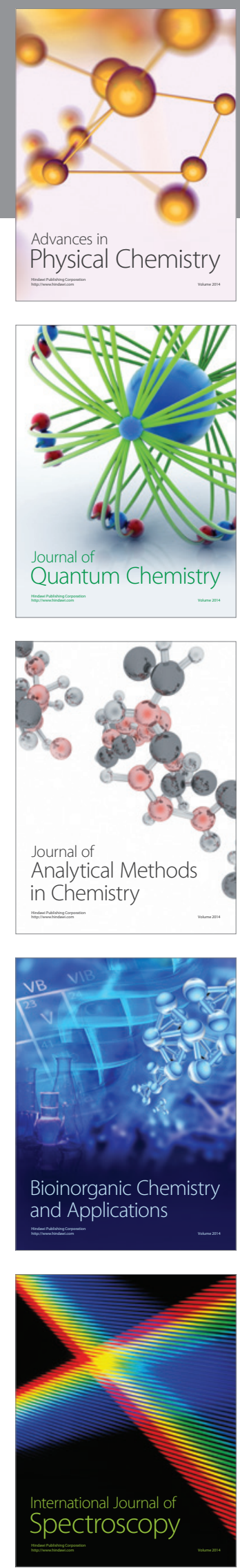